\title{
Immunization policies for employees of childcare facilities within the North Central Health District of Georgia
}

\author{
Paula Kamara, MPH, ${ }^{1}$ Brad Lian, PhD, ${ }^{2}$ Jimmie H. Smith, MD, MPH, ${ }^{1}$ and Judy McChargue, $\mathrm{RN}^{3}$
}

${ }^{1}$ Department of Public Health, Mercer University, Atlanta, GA; ${ }^{2}$ Department of Community Medicine, Mercer University, Macon, GA; and

${ }^{3}$ Georgia Department of Public Health, North Central Health District, Macon, GA

\begin{abstract}
Background: Since the early 1980s, vaccinations have generally been required for children in licensed daycare and school settings. In these settings, vaccinations have reduced disease rates. Adults occupy these settings as well, and ensuring they are vaccinated should also reduce the potential for disease and disease transmission. Yet, there are few vaccination requirements for adults employed at daycare facilities, although such requirements have been recommended (CDC Adult immunization schedule, 2015; ACIP General Recommendations, 2011). The objective of this study was to examine current vaccination policies among childcare facilities within Georgia's North Central Health District (District 5-2) and the climate for possible policy directives in the future.
\end{abstract}

Methods: A 10-item questionnaire regarding vaccination requirements and policies and the importance of vaccination education was mailed to administrators of all 271 licensed childcare facilities within the North Central Health District in Georgia. A total of 76 questionnaires were returned, representing a $28 \%$ response rate. The district has approximately 530,000 residents and is comprised of 13 counties.

Results: Of the childcare facilities, $79 \%$ have no vaccination policies in place. However, most facility directors (75\%) indicated that such policies should be required, and $93 \%$ stated that vaccination education is important for their staff members.

Conclusions: Vaccination requirements can help protect children and their caregivers from communicable diseases. From a policy perspective, the climate may be favorable for the implementation of such requirements, in that most childcare directors recognize the importance of such policies and state that they should be required.

Key Words: immunization, childcare, health, Georgia, policies, workforce

\section{INTRODUCTION}

An estimated $66 \%-80 \%$ of children under the age of 6 spend time in non-parental, out-of-home early education or childcare settings (Shope, 2014), which are relatively highrisk with respect to the transmission and spread of communicable infections and diseases. Consequently, vaccinations are prerequisites for enrollment in these facilities, although policies may vary by state because there is no federal policy (i.e., the constitutional basis for such requirements rests at the state level) (Hodge \& Gostin, 2002; Malone \& Hinman, 2007; Cole \& Swendiman, 2014). Georgia law, for instance, requires that parents or guardians must provide a certificate of immunization for Tdap (a single vaccination for tetanus, diphtheria, and pertussis), varicella (chickenpox), and hepatitis A and B before their children can be admitted to any licensed childcare facility (GDPH Immunization Guidelines for Schools and Childcare Facilities, 2014; see Appendix A). According to a systematic review by the Task Force on Community Preventive Services (Hedden, Jessop, \& Field, 2014), such requirements have proven effective in reducing disease rates in these settings.
In 2012, there were an estimated 1,312,700 employed caregivers in these settings (US Bureau of Labor Statistics, 2014). These caregivers are also vulnerable to communicable diseases and can pass on such diseases and infections to others (and fetuses) (Swanson, \& Piotrkowski, 1994). Close personal contact with the children they care for is a part of their job. Many are also involved in facility activities, such as diaper changing, toileting care, janitorial functions, and first aid, all of which may be performed several times daily (Swanson, \& Piotrkowski, 1994; Bright \& Calabro, 1999; Cordell et al., 2004). Indeed, diarrheal diseases such as giardia, cryptosporidium, and rotavirus, and other infections such as shigella, Escherichia coli, and hepatitis are common among workers in these locations (Cordell et al., 2004). For instance, Slack-Smith et al. (2006) found that $74 \%$ of caregivers at childcare centers and $12 \%$ of caregivers at family daycare facilities reported taking sick leave due to contracting an infectious disease at work. Many of these vaccine-preventable illnesses and diseases are then passed on to other family members and friends (Martin and Khetsuriani, 2000, Cordell et al., 2004; Slack-Smith et al., 2006, DeGreet et al., 2010). 
Nevertheless, adult vaccination levels remain low even though safe and effective vaccines are widely available (National Vaccine Program Office, 2015).

Vaccination requirements for adults working in childcare facilities have been recommended (CDC Adult immunization schedule, 2015; Advisory Committee on Immunization Practices, 2011; see Appendices B and C). The CDC's Advisory Committee on Immunization Practices (ACIP) recommends 13 different vaccinations for adults; each year, they release a recommended adult immunization schedule. For 2015, recommended adult immunizations include, but are not limited to vaccines for influenza, Haemophilus influenza type b, Td/Tdap (tetanus, diphtheria, and pertussis), zoster (shingles), pneumococcal, meningococcal, MMR (measles, mumps, and rubella), hepatitis A and B, varicella (chickenpox), and human papillomavirus (HPV) (CDC Adult immunization schedule, 2015). Boosters or additional doses of vaccines may be needed for some vaccine-preventable diseases, as the immune response to some communicable diseases may weaken over time (ACIP, 2011). It has been proposed that national childcare accreditation and licensing requirements include documenting vaccination of childcare workers and monitoring the development and implementation of policies regarding the vaccination of workers (Hedden, Jessop, \& Field, 2014; Hope et al., 2012). Expanding vaccination requirements to include adults in childcare settings, where the risks for disease transmission and contraction are high, will reduce these risks for the adults, their families, and the children they care for, thus benefitting public health. Doing so should be a priority for health and safety professionals.

\section{PURPOSE}

The status of adult vaccination requirements were assessed with respect to childcare facilities within Georgia's North Central Health District (NCHD, District 5-2), a diverse district consisting of 13 urban and rural counties. Policies were examined by location (urban-rural) and enrollment size. This was accomplished based on responses to a 10item questionnaire mailed to all licensed childcare facilities within the district. The climate for the possible implementation of vaccination requirements for workers in these facilities with respect to the perceived importance and appropriateness of such requirements was also assessed.

\section{METHODS}

The GDPH defines a childcare facility as a public or private center or nursery intended for the care, supervision, or instruction of children (GDPH Immunization Guidelines for Schools and Childcare Facilities, 2014). The Georgia Department of Early Care and Learning website contains a list of addresses and contact information (Bright from the Start) for all such facilities in the state. Three types of facilities are represented in the list: Childcare Learning Centers, which are facilities licensed for 19 or more children; Group Daycare Homes, facilities licensed for 7-18 children; and Family Daycare Homes, facilities licensed for 3-6 children. Most of these provide childcare (for 8-12 hours a day) or preschool services for 0-4-year-old children.
There are 271 such facilities in Georgia's North Central Health District, the setting for this study.

\section{The North Central Health District in Georgia}

The North Central Health District (NCHD, District 5-2), located in middle Georgia, is comprised of 13 counties with 525,929 residents (OASIS, 2013). The district is predominantly rural, in that 10 counties (Crawford, Hancock, Jasper, Jones, Monroe, Peach, Putnam, Twiggs, Washington, and Wilkinson; total population of 177,511, with a racial distribution of $63.1 \%$ White, $34.6 \%$ Black or African American, $0.7 \%$ Asian, 0.4\% American Indian or Alaska Native, and $0.1 \%$ Native Hawaiian or Pacific Islander and an average age of 41 years old) are classified as rural; only 3 counties (Baldwin, Bibb, and Houston; total population of 348,418 , with a racial distribution of $53.6 \%$ White, 41.9\% Black or African American, 2.2\% Asian, $0.3 \%$ American Indian or Alaska Native, and $0.1 \%$ Native Hawaiian or Pacific Islander with an average age of 35 years old) are urban (Georgia Department of Community Health, 2008; OASIS, 2013). The goal of the NCHD is to help residents achieve optimal health and to prevent diseases, promote health, and protect communities against health threats (NCHD, 2013).

\section{Sample and Procedures}

The population list for the study was the 271 childcare facilities in the NCHD recognized by the Georgia Department of Early Care and Learning. Larger counties (with respect to population) in the district had more childcare facilities, but each county had at least two facilities.

A packet containing a cover letter explaining the purpose of the research, assurances of confidentiality, a 10-item questionnaire, and a prepaid (stamped) return envelope was mailed to each facility on the list. The questionnaire, designed to require about 5 minutes to complete, included items concerning the county in which the facility is located, the number of children enrolled, number of staff members employed, vaccination record requirements, the presence of policies that promote vaccination and proof of vaccination, and the importance of educating childcare staff about vaccinations (See Appendix D). The director of the facility or an employee familiar with the facility's workforce and policies was asked to complete the questionnaire and return it within 30 days. Our gratitude was the only compensation offered.

\section{RESULTS}

\section{Description of Respondent Centers}

Of the 271 questionnaires, 76 were returned over the monthlong period allowed for data collection, for a response rate of $28 \%$. Each county was represented in the sample; response rates for each county are listed in Table 1 . The facilities represented had a total of 773 childcare workers and 4,305 children, which translates to an average of 57 children per facility and to a children-to-staff ratio of about 6:1. 
Overall, $63 \%$ of the returned surveys were from childcare facilities in urban counties and $37 \%$ were from facilities in rural counties. A variety of facility sizes, in terms of enrollment, were represented. Facilities with 0-6 children comprised $27 \%(\mathrm{n}=20)$ of the sample, those with 7-20 children represented $10 \%(n=8)$ of the sample, and those with $21-75$ and 76 or more children represented $31 \%$ (each $\mathrm{n}=24$ ) of the sample. Facilities were typically smaller in the rural areas. Of these facilities, $44 \%$ had an enrollment size of $0-6$ children; in the urban counties, $40 \%$ had an enrollment size of 76 children or greater. This difference in enrollment sizes with respect to the location was apparently related to different levels of population density and to travel times associated with living in the different areas (i.e., more people in smaller areas was conducive to larger enrollment sizes).

\section{Urban-Rural Differences}

As determined by chi-square tests, no statistically significant differences were evident based on facility location. That is, the responses were similar for the urbanand rural-based facilities. Of the rural-based respondents, $73 \%$ (19/26) did not require that staff provide proof of vaccination upon hiring, and $89 \%$ (42/47) of those in urban areas had no such requirement. For rural and urban facilities, $72 \%$ and $83 \%$, respectively, did not have vaccination policies in place. Most directors in rural $(96 \%$, 26/27) and urban (91\%, 42/46) areas thought that vaccination education for staff was important. Further, $81 \%$ $(21 / 26)$ of rural directors and $72 \%$ (33/46) of urban directors supported staff requirements of up-to-date vaccination. Finally, 89\% (23/26) of rural directors and 78\% (36/46) of urban directors responded that a vaccine information session would be beneficial for their staff. Again, as determined by chi-square tests, no statistically significant differences were found based on the size of enrollments of the facilities.

\begin{tabular}{|l|c|c|c|c|}
\hline Table 1: North Central Health District Sample Breakdown & $\begin{array}{c}\text { Number of children } \\
\text { Cumber of } \\
\text { facilities in } \\
\text { county }\end{array}$ & County response rate & $\begin{array}{c}\text { Number of workers } \\
\text { facilities }\end{array}$ & $\begin{array}{c}\text { in responding } \\
\text { facilities }\end{array}$ \\
\hline Urban counties & & & & 178 \\
\hline Baldwin & 24 & $46 \%(\mathrm{n}=11)$ & 1041 & 143 \\
\hline Bibb & 102 & $17 \%(17)$ & 1301 & 231 \\
\hline Houston & 70 & $28 \%(20)$ & 3292 & 552 \\
\hline \multicolumn{1}{|c|}{ Urban total } & 196 & $25 \%(48)$ & & 14 \\
\hline Rural counties & & & 68 & 3 \\
\hline Crawford & 2 & $50 \%(1)$ & 15 & 13 \\
\hline Hancock & 5 & $60 \%(3)$ & 106 & 41 \\
\hline Jasper & 2 & $50 \%(1)$ & 102 & 47 \\
\hline Jones & 10 & $50 \%(5)$ & 219 & 22 \\
\hline Monroe & 11 & $36 \%(4)$ & 110 & 24 \\
\hline Putnam & 7 & $29 \%(2)$ & 122 & 13 \\
\hline Peach & 16 & $38 \%(6)$ & 45 & 22 \\
\hline Twiggs & 2 & $50 \%(1)$ & 140 & 22 \\
\hline Washington & 15 & $13 \%(2)$ & 86 & 773 \\
\hline Wilkinson & 5 & $60 \%(3)$ & 1013 & \\
\hline Rural total & 75 & $37 \%(28)$ & 4305 & \\
\hline Total & 271 & $28 \%(76)$ & & \\
\hline
\end{tabular}


Table 2: Frequency of Vaccination Policies among Daycare Facilities in the North Central Health District (District 5-2)

\begin{tabular}{|c|c|c|c|}
\hline & Total $(n=73)$ & Rural $(n=26)$ & Urban $(n=47)$ \\
\hline \multicolumn{4}{|c|}{ Vaccination Records Required When Hiring } \\
\hline Yes & $16 \%(\mathrm{n}=12)$ & $27 \%(7)$ & $11 \%(5)$ \\
\hline No & $84 \%(61)$ & $73 \%(19)$ & $89 \%(42)$ \\
\hline \multicolumn{4}{|c|}{ Vaccination Policy in Place } \\
\hline Yes & $21 \%(15)$ & $28 \%(7)$ & $17 \%(8)$ \\
\hline No & $79 \%(56)$ & $72 \%(18)$ & $83 \%(38)$ \\
\hline \multicolumn{4}{|c|}{ Frequency of Vaccination Record Review (for those who have policies) } \\
\hline 6 months or less & $7 \%(2)$ & $14 \%(2)$ & $0 \%(0)$ \\
\hline Every year & $27 \%(8)$ & $36 \%(5)$ & $19 \%(3)$ \\
\hline Every 2 years & $7 \%(2)$ & $14 \%(2)$ & $0 \%(0)$ \\
\hline Every 5 Years & $7 \%(2)$ & $0 \%(0)$ & $13 \%(2)$ \\
\hline Not Reviewed & $17 \%(5)$ & $14 \%(2)$ & $19 \%(3)$ \\
\hline I Don't Know & $37 \%(11)$ & $21 \%(3)$ & $50 \%(8)$ \\
\hline \multicolumn{4}{|c|}{ Importance of Vaccination Education } \\
\hline Not Important & $7 \%(5)$ & $4 \%(1)$ & $9 \%(4)$ \\
\hline Somewhat important & $26 \%(19)$ & $22 \%(6)$ & $28 \%(13)$ \\
\hline Very important & $67 \%(49)$ & $74 \%(20)$ & $63 \%(29)$ \\
\hline \multicolumn{4}{|c|}{ Staff Requirement of Up-To-Date Vaccination } \\
\hline Yes & $75 \%(54)$ & $81 \%(21)$ & $72 \%(33)$ \\
\hline No & $25 \%(18)$ & $19 \%(5)$ & $28 \%(13)$ \\
\hline \multicolumn{4}{|c|}{ How Beneficial is Vaccine Information Session for Staff } \\
\hline Extremely & $40 \%(29)$ & $50 \%(13)$ & $35 \%(16)$ \\
\hline Somewhat & $19 \%(14)$ & $23 \%(6)$ & $17 \%(8)$ \\
\hline Beneficial & $22 \%(16)$ & $15 \%(4)$ & $26 \%(12)$ \\
\hline Not Beneficial & $8 \%(6)$ & $4 \%(1)$ & $11 \%(5)$ \\
\hline Not important & $10 \%(7)$ & $8 \%(2)$ & $11 \%(5)$ \\
\hline
\end{tabular}

\section{DISCUSSION}

While public health efforts have been made to ensure vaccinations for children in childcare facilities, there are no such requirements for the adults in these relatively high-risk environments. Nevertheless, requirements and monitoring mechanisms have been recommended (CDC Adult immunization schedule, 2015; ACIP, 2011), based on the notion that expanded coverage reduces health risks.

The present study assessed the current state of vaccination requirements and polices among childcare facilities within Georgia's NCHD. It also assessed whether such policies should be required and if educating staff on the importance and utility of vaccinations would be helpful.

A large portion (79\%) of childcare facilities within the NCHD did not have policies that require workers to be vaccinated, and $83 \%$ did not require that workers provide vaccination records upon hiring. Most respondents (75\%), however, indicated that childcare workers should be required to have updated vaccinations. A few of the questionnaires that were returned contained unsolicited remarks stating that the reason no policies are in place is because the state has not required them. These comments suggest that facilities would likely follow the lead of the state on the matter. Further, more than $90 \%$ of the survey respondents think that educating staff members about vaccines is important. However, there were no statistically significant differences in the responses to the questionnaire items based on the location (urban/rural) or enrollment size of the facility (small to large), suggesting that the findings may be generalizable across settings and facility sizes.

In sum, most of the childcare facilities in the NCHD do not have policies or vaccination requirements for staff but feel 
that they are important. Without encouragement from the state, the status quo seems likely to continue. Because most childcare centers indicated that vaccination requirements should be implemented and recognized the importance of having such requirements in place, however, the environment appears to be favorable for acceptance of such a policy directive from the state.

\section{Limitations}

A potential limitation of this study is that the overall response rate was only $28 \%$. Higher response rates are typically associated with more confidence in the capacity to generalize findings. Nevertheless, a variety of facilities from different locations were represented, and the findings were consistent across settings and enrollment sizes. Another limitation with respect to potential policy prescriptions is that the sample is based solely on licensed childcare facilities. Presumably, larger childcare facilities are licensed, but some, particularly smaller informal care providers, may not be. We have no data on the policies of unlicensed facilities.

\section{Implications for Public Health}

Recommendations stemming from this research have implications for public health and advocacy efforts. For instance, recommending that adults working at childcare facilities be vaccinated and that vaccination updates be maintained, as suggested by the CDC, seems sensible. Such requirements have proven to be effective in reducing the spread of illnesses and diseases in these locations, and expanding the requirements to include adults would reduce the potential for and the spread of disease (Hedden, Jessop, \& Field, 2014). In short, vaccination requirements for adults in these settings would promote public health.

The current climate may be favorable for advocating the application of such policies. It may be best to target advocacy efforts to implementing directives regarding vaccination policies and enforcement at accreditation and licensing agencies. Doing so may expedite and promote the standardization of policies, which would help facilitate updated documentation/record-keeping and the transferability and linking of records and data across counties.

In particular, the recommendation that accrediting and licensing agencies enforce guidelines listed in a national plan for staff vaccination (Hope et al., 2012) should be instituted. The guidelines are as follows:

- Develop a staff immunization policy that outlines the immunization requirements for childcare staff in the national immunization handbook.

- Develop a staff immunization record; this should document previous infections or immunizations for the relevant diseases.

- $\quad$ Require all new and current staff to complete the staff immunization record.

- Regularly update staff immunization records as staff become vaccinated.

- Provide staff with information about diseases that are preventable by immunization, for example, through in-service training and written materials such as fact sheets.

It may be helpful also to advocate for awareness and education campaigns with respect to adult vaccinations at childcare facilities throughout the state. Awareness and education are associated with policy formation and implementation and consequently with vaccination rates (de Perio, Wiegand, \& Evans, 2012; Spokes, Ferson, \& Ressler, 2011; Thomson, Kennedy, \& Thompson, 1998). Hayney and Bartell (2005), for instance, found that vaccination rates increased from $30 \%$ to $60 \%$ among daycare workers after they received education on vaccinations and the spread of disease. Distributing the CDC's Adult Immunization Schedule (Appendix B) to childcare workers along with the vaccination guidelines provided by its Advisory Committee on Immunization Practices and the Georgia Department of Public Health, would aid in increasing awareness about vaccinations for adults and thus increase immunization coverage. In addition, the vaccination quiz (Appendix C) listed on the CDC website can help workers determine what specific vaccines are recommended for them.

Educating the directors of these facilities on the occupational, health, and financial benefits associated with vaccinating staff members would also be helpful. From an economic perspective, directors should understand that the time lost from work and that the cost of replacing a sick worker outweighs the time taken to vaccinate workers (Slack-Smith et al., 2006; Spokes, Ferson, \& Ressler, 2011). Although many vaccinations may be covered by insurance, informing directors about available state grant programs for vaccinations may alleviate concerns about costs associated with vaccinations of staff members. For example, the CDC Grant Immunization Program is a federally funded entitlement program that provides vaccines at no cost to eligible children, adolescents, and adults who are uninsured or underinsured (CDC, 2007). Individuals meeting these requirements may receive vaccinations at Federally Qualified Health Centers (FQHC), Rural Health Clinics (RHC), or local health departments (CDC, 2012).

All states currently have vaccination requirements in place for children attending childcare facilities, but none have policies with respect to the workforce in such facilities. Advocating for and implementing vaccination requirements for the workers at these facilities are supported by evidence and by the intended audience(s). Such requirements will benefit public health by protecting childcare workers, their friends and families, and the children they all care for from communicable diseases.

\section{Acknowledgements}

The authors would like to thank all of the childcare directors in the sample for taking the time to participate in this study. We also appreciate all of the helpful comments and advice from the reviewers.

\section{References}

Advisory Committee on Immunization Practices (ACIP). (2011).Morbidity and Mortality Weekly Report (MMWR), 60(29), 977-1007. Retrieved from http://www.cdc.gov/mmwr/preview/mmwrhtml/rr6002a1.htm 
Bright, K. A., \& Calabro, K. (1999). Child care workers and workplace hazards in the United States: Overview of research and implications for occupational health professionals. Occupational Medicine, 49(7), 427-437.

CDC. (2007). Immunization grant program (section 317). Retrieved

from http://www.cdc.gov/vaccines/programs/vfc/downloads/grant317.pdf

CDC. (2012. Questions Answered on Vaccines Purchased with 317 funds. Retrieved from http://www.cdc.gov/vaccines/imzmanagers/guides-pubs/qa-317-funds.html

CDC. (2014). Immunization schedules. Retrieved from http://www.cdc.gov/vaccines/schedules/index.html [Retrieved on October 24, 2014]

CDC. (2015). Recommended adult immunization schedule. Retrieved from http://www.cdc.gov/vaccines/schedules/hcp/adult.html

Cole, J. P., \& Swendiman, K. S. (2014). Mandatory vaccinations: Precedent and current laws. Congressional Research Service, 111.

Cordell, R., Pickering, L., Henderson, F. W., \& Murph, J. (2004). Infectious Diseases in Childcare Settings. Emerging Infectious Diseases, 10(11), e9. doi:10.3201/eid1011.040623_04

de Perio, M.A., Wiegand, D. M., \& Evans, S. M. (2012). Low influenza vaccination rates among child care workers in the United States: Assessing knowledge, attitudes, and behaviors. Journal of Community Health, 37(2), 272-81. doi:http://dx.doi.org/10.1007/s10900-011-9478-z

DeGreet, S. C., Mooi, F. R., Westerhof, A., Verbakel, J. M., Peeters, M. F., Heuvelman, C. J., \& de Melker, H. E. (2010). Pertussis Disease Burden in the Household: How to Protect Young Infants. Clinical Infectious Diseases, 50(10), 1339-1345.

Georgia Department of Public Health (GDPH). (2014). Immunization guidelines for schools and childcare facilities. Retrieved

from http://dph.georgia.gov/sites/dph.georgia.gov/files/Immunizations Immunization Guidelines for Schools and Childcare Facilities form 3258_0.pdf

Georgia Department of Community Health. (2008). Georgia rural county map. Retrieved from https://dch.georgia.gov/documents/georgia-rural-county-map

Georgia Department of Early Care and Learning. (2014). Provider search. Retrieved from http://decal.ga.gov/ProviderSearch/SiteSearch.aspx ?childcare $=y$ \&newsearch $=\mathrm{y}$

Georgia Department of Community Health, Division of Public Health, Office of Information and Policy. (2013). Online Analytical Statistical Information System (OASIS). Retrieved from http://oasis.state.ga.us/CHNADashboard/Default.aspx

Hayney, M. S., \& Bartell, J. C. (2005). An immunization education program for childcare providers. Journal of School Health, 75(4), 147-149. doi:10.1111/j.1746-1561.2005.00014.x

Hedden, E. M., Jessop, A. B., \& Field, R. I. (2014). An Education in Contrast: State-by-State Assessment of School Immunization
Records Requirements. American Journal of Public Health, 104(10), 1993-2001. doi:10.2105/AJPH.2014.302078

Hodge, J. G., \& Gostin, L. O. (2002). School vaccination requirements: Historical, social, and legal perspectives. Center for Law and the Public's Health, 1-72.

Hope, K., Butler, M., Massey, P., Cashman, P., Durrheim, D., Stephenson, J., \& Worley, A. (2012). Pertussis vaccination in Child Care Workers: Room for improvement in coverage, policy and practice. BMC Pediatrics, 98-98.

Malone, K. M., \& Hinman, A. R. (2007). Vaccination Mandates: The Public Health Imperative and Individual Rights. In R. A. Goodman, R.E. Hoffman, W. Lopez, G.W. Matthews, M.A. Rothstein \& K. L. Foster (Eds.), Law in Public Health Practice (p.262-283). Madison Avenue, New York: Oxford University Press, Inc.

Martin, R., \& Khetsuriani. N. (2000). School and Child Care Settings. In Centers for Disease Control and Prevention (Ed.), School and Child Care Settings (ch 8). Atlanta, Georgia. Retrieved from http://www.cdc.gov/pertussis/outbreaks/guide/

National Vaccine Program Office. (2015). Draft Report, National Adult Immunization Plan. Retrieved from http://hhs.gov/nvpo/vacc_plan/index.html

North Central Health District. (2013). North central health district 2013 population census estimates. Retrieved from http://northcentralhealthdistrict.org/wpcontent/uploads/2013/08/districtmap 2013estimates.pdf

Online Analytical Statistical Information System (OASIS). (2013). Georgia Department of Public Health, Office of Health Indicators for Planning (OHIP). Retrieved from http://oasis.state.ga.us/

Slack-Smith, L. M., Read, A. W., Darby, J. J., \& Stanley, F. J. (2006). Health of caregivers in child care. Child: Care, Health \& Development, 32(1), 111-119. doi:10.1111/j.13652214.2006.00577.x

Shope, T. R. (2014). Infectious diseases in Early Education and Child Care Programs. Pediatrics in Review, 35(5), 182-93.

Spokes, P. J., Ferson, M. J., \& Ressler, K. (2011). Staff immunisation: Policy and practice in child care. Journal of Paediatrics \& Child Health, 47(8), 530-534. doi:10.1111/j.14401754.2011.02016.x

Swanson, N. G., \& Piotrkowski, C. S. (1994). Occupational health and safety issues in child-care work. Pediatrics, 94(6), 1079.

Thomson, J. A., Kennedy, R., \& Thompson, S. C. (1998). Hepatitis A vaccination of child care Workers in Victoria: Are recommendations being implemented? Australian and New Zealand Journal of Public Health, 22(7), 832-834. Retrieved from

http://search.proquest.com/docview/215710735?accountid=1238 1

U.S. Bureau of Labor Statistics. (2014). Childcare workers. Retrieved from http://www.bls.gov/ooh/Personal-Care-andService/Childcare-workers.html 


\section{T. Summary of Georgia Immunization Requirements for Child Care \& School Attendance}

These charts are based on the ACIP Recommendations and Georgia Requirements; for more detailed information including dose schecules and minimum time intervals; please refer to Georgia Form 3231REQ and Table 1 of the ACIP General Recommendations,

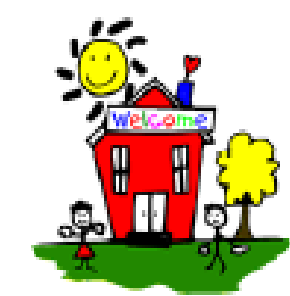
MMWR, January 28, 2011.

Required Number of Doses for Children Who Started Immunizations before Age 7 Years

\begin{tabular}{|c|c|c|c|c|c|c|c|c|c|}
\hline $\begin{array}{l}\text { Required } \\
\text { Vaccines }\end{array}$ & $\begin{array}{c}2 \\
\text { mo }\end{array}$ & $\begin{array}{c}4 \\
\text { mo }\end{array}$ & $\begin{array}{c}6 \\
\text { mo }\end{array}$ & $\begin{array}{l}12 \\
\text { mo }\end{array}$ & $\begin{array}{l}15 \\
\text { mo }\end{array}$ & $\begin{array}{l}18 \\
\text { mo }\end{array}$ & $\begin{array}{l}24 \\
\text { mo }\end{array}$ & $\begin{array}{c}4-6 \\
\text { years }\end{array}$ & $\begin{array}{c}\text { 5-6 yrs of age } \\
\text { Total Doses Required for School Entry }\end{array}$ \\
\hline $\begin{array}{r}\text { DTP, DT, } \\
\text { DTaP }\end{array}$ & 1 & 2 & 3 & \multicolumn{3}{|c|}{4} & & 5 & $\begin{array}{c}4 \text { or } 5 \\
\text { (if } \# 4 \text { dose given on or after } 4 \text { th birthday, } \\
\# 5 \text { not needed) }\end{array}$ \\
\hline Hep B & 1 & 2 & \multicolumn{4}{|c|}{3} & & & 3 \\
\hline Hib & 1 & 2 & 3 & \multicolumn{2}{|c|}{4} & & & & \\
\hline $\begin{array}{l}\text { (ActhiB) } \\
\text { or } \\
\text { Hib } \\
\text { (PedvaxHIB } \\
\text { or Coinvax) }\end{array}$ & 1 & 2 & & \multicolumn{2}{|c|}{3} & & & & $\begin{array}{l}\text { Required for } \\
\text { Child Care and Pre-K only }\end{array}$ \\
\hline$\because$ Polio & 1 & 2 & \multicolumn{4}{|c|}{3} & & 4 & $\begin{array}{c}\text { 3or } 4 \\
\left(4^{\text {th }} \text { dose of polio on or after } 4^{\text {th }} \text { birthday }\right. \\
\text { required for children bom on } \\
\text { or after } 1-1-06)\end{array}$ \\
\hline 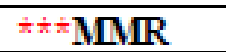 & & & & \multirow{2}{*}{\multicolumn{2}{|c|}{1}} & & & 2 & 2 \\
\hline Varicella & & & & & & & & 2 & 2 \\
\hline PCV & 1 & 2 & 3 & \multicolumn{2}{|c|}{4} & & & & Required for Child Care \& Pre-K only \\
\hline Hep A & & & & \multicolumn{3}{|c|}{1} & \multicolumn{2}{|c|}{2} & $\begin{array}{c}2 \\
\text { Required for children born on or after } \\
1-1-06 \\
\end{array}$ \\
\hline
\end{tabular}

"If PedvaxHIB or Comax is administered at ages 2 and 4 months, a dose at 6 months is not indicated.

** The final dose in the series should be administered on or after the fourth birthday and at least 6 months following the previous dose.

If 4 doses are administered prior to age 4 years a fifth dose should be administered at age 4 through 6 years. (MMWR 2009; $58(30)$ :829-30)

***State requirement is for 2 doses each of measles and mumps, and 1 dose of rubella vaccine. Second dose may be given before age

4 years, provided at least 4 weeks have elapsed since first dose.

http://dph.georgia.gov/schools-and-childcare 
APPENDIX A Cont.

\section{Vaccination requirements for Georgia, Childcare, and all vaccines.}

\begin{tabular}{|l|l|l|l|l|}
\hline \multicolumn{1}{|c|}{ Vaccine } & Doses & \multicolumn{1}{|c|}{ Details } & $\begin{array}{c}\text { Effective } \\
\text { Date }\end{array}$ & $\begin{array}{c}\text { Additional } \\
\text { Comments }\end{array}$ \\
\hline $\begin{array}{l}\text { DTaP-Diphtheria, } \\
\text { Tetanus, acellular } \\
\text { Pertussis }\end{array}$ & 3 & $\begin{array}{l}\text { Age appropriate dosing following } \\
\text { ACIP recommendations }\end{array}$ & $\begin{array}{l}\text { PRIOR to } \\
2008-09\end{array}$ & \\
\hline $\begin{array}{l}\text { Flu-Influenza } \\
\text { (seasonal) }\end{array}$ & 0 & No state requirement & $\begin{array}{l}\text { Not } \\
\text { applicable }\end{array}$ & \\
\hline Hep A-Hepatitis A & 2 & All children born after 1/1/06 & $\begin{array}{l}\text { PRIOR to } \\
\text { 2008-09 }\end{array}$ & \\
\hline Hep B-Hepatitis B & 3 & $\begin{array}{l}\text { Age appropriate dosing following } \\
\text { ACIP recommendations }\end{array}$ & $\begin{array}{l}\text { PRIOR to } \\
2008-09\end{array}$ & \\
\hline $\begin{array}{l}\text { Hib-Haemophilus } \\
\text { Influenzae Type B }\end{array}$ & $3-4$ & $\begin{array}{l}\text { Age appropriate dosing following } \\
\text { ACIP recommendations }\end{array}$ & $\begin{array}{l}\text { PRIOR to } \\
2008-09\end{array}$ & \\
\hline $\begin{array}{l}\text { MMR-Measles, } \\
\text { Mumps, Rubella }\end{array}$ & 1 & After age 1 year & $\begin{array}{l}\text { PRIOR to } \\
2008-09\end{array}$ & \\
\hline $\begin{array}{l}\text { PCV-Pneumococcal } \\
\text { Conjugate Vaccine }\end{array}$ & 4 & $\begin{array}{l}\text { Age appropriate dosing under age 5 5 } \\
\text { years }\end{array}$ & $\begin{array}{l}\text { PRIOR to } \\
2008-09\end{array}$ & \\
\hline Polio & $3-4$ & Age appropriate dosing & $\begin{array}{l}\text { PRIOR to } \\
2008-09\end{array}$ & \\
\hline VAR-Varicella & 1 & $\begin{array}{l}\text { After age 1 year or disease history } \\
\text { or physician diagnosis }\end{array}$ & $\begin{array}{l}\text { PRIOR to } \\
2008-09\end{array}$ & \\
\hline
\end{tabular}

http://www2a.cdc.gov/nip/schoolsurv/schImmRqmt.asp 
APPENDIX B

CDC Recommended immunization meanings and doses for adults

\begin{tabular}{|c|c|c|c|c|}
\hline Vaccine & Abbreviation & Dose & Booster & Age groups \\
\hline Inactivated influenza (flu) & IIV & 1 & Every year & 19 and up \\
\hline Tetanus, diphtheria, pertussis & TDaP & 1 & Every 10 years & 19 and up \\
\hline Varicella-chicken pox & VAR & 2 & & 19 and up \\
\hline HPV vaccine for women & HPV & 3 & & $19-26$ \\
\hline HPV vaccine for men & HPV & $\begin{array}{l}6 \text { (first } 3 \text { for } \\
19-21 \text { yrs and } \\
\text { last } 3 \text { for } 21- \\
26 \text { yrs) }\end{array}$ & & $19-26$ \\
\hline Herpes Zoster shingles & $\mathrm{HZV}$ & 1 & & $60-65$ \\
\hline Measles, Mumps, Rubella & MMR & $1-2$ & & $19-55$ \\
\hline Pneumococcal & PCV13 & 1 & & 19 and up \\
\hline Pneumococcal & PPSV23 & $\begin{array}{l}1 \text { or } 2 \text { ( } 1 \text { at } \\
19-64 \text { yrs or } \\
\text { another one } \\
\text { at } 65+\text { years) }\end{array}$ & & 19 and up \\
\hline Meningococcal & MCV & 1 or more & & 19 and up \\
\hline Hepatitis A & Hep A & 2 & & 19 and up \\
\hline Hepatitis B & Hep B & 3 & & 19 and up \\
\hline Haemophilus influenzae type b & Hib & 1 or 3 doses & & 19 and up \\
\hline
\end{tabular}

***Multivalent vaccine-vaccine that protects against multiple different strains of a microorganism

http://www.cdc.gov/vaccines/schedules/hcp/imz/adult.html 


\section{$\underline{C D C}$ 's Adolescent and Adult Vaccine Quiz}

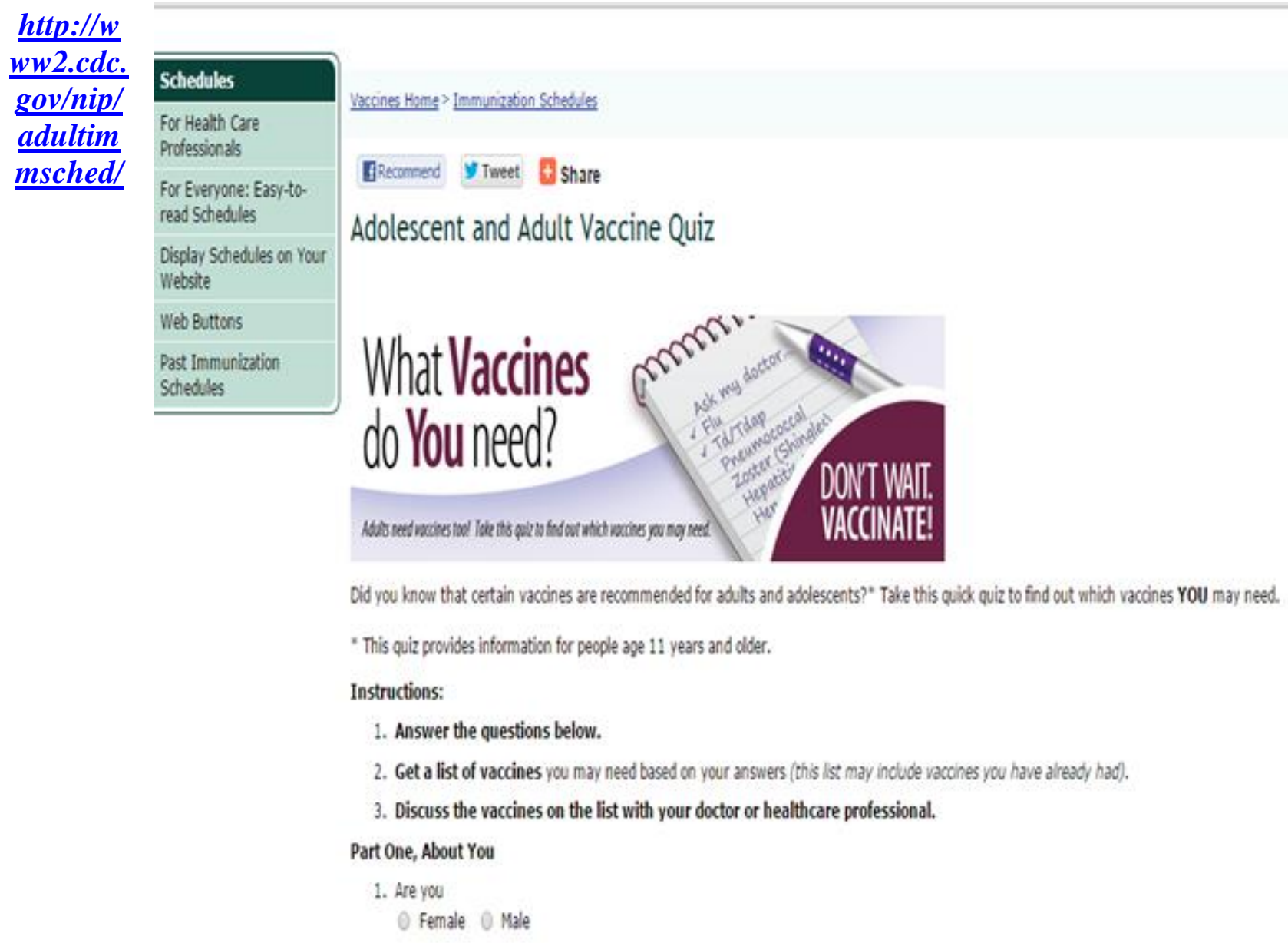




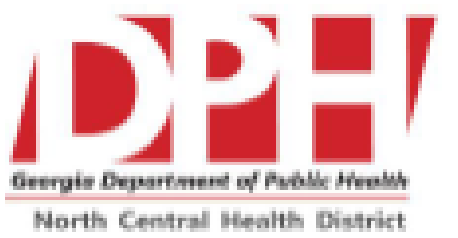

\author{
APPENDIX D \\ Brenda Fitzgerald, MD, Commissioner | Nathan Deal, Governor \\ David N. Harvey, MD, District Health Director \\ 201 Second St. Suite 1100, Macon, GA 31201 \\ Pbone: (478) 751-6303 * Fax: (478) $751-6099$
}

North Central Health District Daycare Worker Vaccination Survey

The purpose of this sunvy is to gain insight on the vaccination policies anong daycare facilities within the North Central Health District.

1. In which county is your daycare center located?

2. What is the zip code of your daycare center?

3. How many children are currently enrolled at your daycare center?

4. How many staff members do you have in the following age ranges?

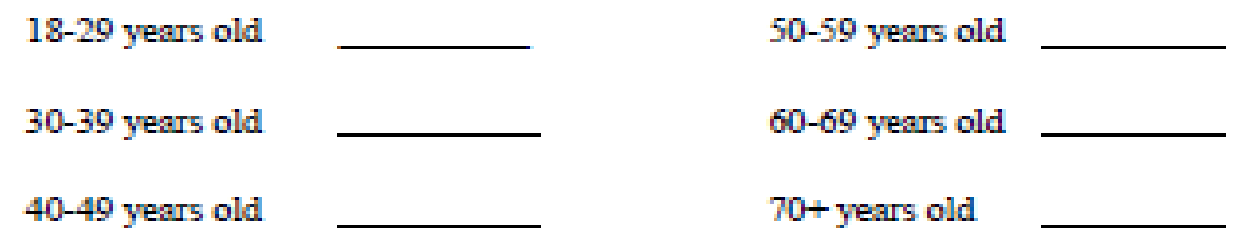

5. When hiring staff members, are vaccination records required?

Yes

No

6. Does the center have a policy that recommends vaccinations or proof of vaccinations for all staff members?

Yes

No 


\section{APPENDIX D Cont.}

7. If yes, how often are your staff's vaccination files reviewed?

Every 6 months or less

Every year

Every 2 years
Every 5 years

Not reviewed after hiring

I do not know

8. How important is it to echucate daycare staff members about vaccinations?

Not important

0 Somewhat important

O Very important

9. Should daycare staff members be required to have up-to-date vaccinations?

Yes

No

10. An informational session on recommended vaccinations would be beneficial for our staff.

Extremely Beneficial
Somewhat beneficial
Beneficial
Not Beneficial
Not important

Thank you for your participation! If you have any questions or concens regarding this suovy. please contact Ms. Paula Kanana, Mercer University Master of Public Health candidate, at pania kannara a ine mercer.edh or (770) 365-6347. 